\title{
Safe decontamination of cytostatics from the nitrogen mustards family. Part one: cyclophosphamide and ifosfamide
}

This article was published in the following Dove Press journal:

International Journal of Nanomedicine

\author{
Irena R Štenglová Netíková \\ Luboš Petruželka ${ }^{2,3}$ \\ Martin Št’astnýl,2 \\ Václav Štengl' \\ 'Department of Oncology, Ist Faculty \\ of Medicine, Charles University and \\ General University Hospital in Prague, \\ Prague, Czech Republic; ${ }^{2}$ Department \\ of Material Chemistry, Institute of \\ Inorganic Chemistry ASCR v.v.i., \\ Řež, Czech Republic; ${ }^{3}$ Faculty of \\ Environment, J.E. Purkyně University \\ in Ústí nad Labem, Ústí nad labem, \\ Czech Republic
}

\begin{abstract}
Introduction: Macrocrystalline oxides of alkaline earth metals ( $\mathrm{Mg}$ and $\mathrm{Ca}$ ) or light metals ( $\mathrm{Al}$ and Ti) can respond to standard warfare agents such as sulfur mustard, soman, or agent VX. In this paper, we compared the decontamination ability of sodium hydroxide $(\mathrm{NaOH})$ and sodium hypochlorite ( $\mathrm{NaClO}$ ) for nitrogen mustards (cyclophosphamide [CP] and ifosfamide [IFOS]) with a new procedure using a destructive sorbent based on nanocrystalline and nanodispersive titanium dioxide $\left(\mathrm{TiO}_{2}\right)$ as a new efficient and cheap material for complete decontamination of surfaces.
\end{abstract}

Methods: Titanium (IV) dioxide nanoparticles were prepared by the homogeneous hydrolysis of titanium(IV) oxysulfate $\left(\mathrm{TiOSO}_{4}\right)$ with urea. The as-prepared $\mathrm{TiO}_{2}$ nanoparticles were used for the fast and safe decontamination of cytostatics from the nitrogen mustard family (CP and IFOS) in water. The adsorption-degradation process of cytostatics in the presence of $\mathrm{TiO}_{2}$ was compared with decontamination agents $(0.01 \mathrm{M}$ solution of sodium hydroxide and $5 \%$ solution of sodium hypochlorite). The mechanism of the decontamination process and the degradation efficiency were determined by high-performance liquid chromatography with mass spectrometry.

Results: It was demonstrated that a $0.01 \mathrm{M}$ solution of sodium hydroxide $(\mathrm{NaOH})$ decomposes CP to 3-((amino(bis(2-chloroethyl)amino)phosphoryl)oxy)propanoic acid and sodium hypochlorite formed two reaction products, namely, IFOS and 4-hydroxy-cyclophosphamide. IFOS is cytotoxic, and 4-hydroxy-cyclophosphamide is a known metabolite of CP after its partial metabolism by CYP/CYP450. IFOS degrades in the pres $\neg$ ence of $\mathrm{NaOH}$ to toxic IFOS mustard. Titanium(IV) dioxide nanoparticles adsorbed on its surface CP after 5 minutes and on IFOS after 10 minutes. The adsorption-degradation process of $\mathrm{CP}$ in water and in the presence of $\mathrm{TiO}_{2}$ led to 4-hydroxy-cyclophosphamide and IFOS, respectively, which decayed to oxidation product 4-hydroxy-ifosfamide.

Conclusion: Nanodispersive $\mathrm{TiO}_{2}$ is an effective degradation agent for decontamination of surfaces from cytostatics in medical facilities.

Keywords: cyclophosphamide, ifosfamide, ifosfamide mustard, titanium(IV) dioxide, degradation, decontamination agents

\section{Introduction}

Macrocrystalline oxides of alkaline earth metals ( $\mathrm{Mg}$ and $\mathrm{Ca}$ ) or light metals ( $\mathrm{Al}$ and $\mathrm{Ti}$ ) can respond to standard warfare agents such as sulfur mustard, soman, or agent VX. ${ }^{1}$ Reactions with the macrocrystalline oxides are slow and unusable for military decontamination practices. However, if the size of the individual oxide particles decreases on the order of 1-10 nm, it is possible to observe an increase in their specific reactivity. Observed acceleration heterogeneous reactions, which take place on the surface of the nanocrystals, have been explained in particular by increasing the proportion of highly reactive sites, such as the edges and corners of nanocrystals in which the amount of dislocations or defects increase. ${ }^{2}$ (c)
hereby accept the Terms. Non-commercial uses of the work are permitted without any further permission from Dove Medical Press Limited, provided the work is properly attributed. For permission for commercial use of this work, please see paragraphs 4.2 and 5 of our Terms (https://www.dovepress.com/terms.php). 
The sulfur mustards family includes eight useful agents, including sulfur mustard bis(2-chloroethyl)sulfide (yperite) used as a chemical warfare agent, which is cytotoxic and acts as a nonspecific DNA alkylating agent. After World War I, there was research into its effect on tumor cells. Cytostatics are first derived from the sulfur mustard, and with a substitution of nitrogen instead of sulfur, we get the nitrogen mustards. In 1942, they were classified to begin human clinical trials of nitrogen mustards for the treatment of lymphoma. ${ }^{3}$ There was an incident during an air raid on Bari (Bari) in World War II, where a release of mustard gas affected hundreds of soldiers and civilians. ${ }^{4}$ On the basis of these past studies, bis(2-chlorethyl)ethylamine, called Mustin, was the first prototype of an anticancer chemotherapeutic. ${ }^{4}$

The nitrogen mustards used as warfare agents include HN1 - bis(2-chlorethyl)ethylamine, HN2 - bis(2-chlorethyl) methylamine, and HN3 - tris(2-chlorethyl)amine, and derivatives from uracil mustard (5-[bis(2-chloroethyl) amino]-1H-pyrimidine-2,4-dione) that are used as cytotoxic chemotherapy agents include cyclophosphamide (CP) ( $N, N$-bis(2-chlor)), chlorambucil(4-[bis(2-chlorethyl) amino]benzenebutanoic acid), ifosfamide (IFOS) ( $N, 3-$ bis(2-chloroethyl)-1,3,2-oxazaphosphinan-2-amide 2-oxide), melphalan (4-[bis(2-chloroethyl)amino]-L-phenylalanine), and bendamustine (4-[5-[bis(2-chloroethyl)amino]-1-methylbenzimidazol-2-yl]butanoic acid).

$\mathrm{CP}$ is the most common and most versatile cytostatic. It is a unique alkylating cytostatic agent for the following reasons: $\mathrm{CP}$ alone is ineffective; the cytostatic effect is due to its metabolite formed in the liver - 4-hydroxy-cyclofosfamide. The treatment affects the microsomal enzyme system and CYP/CYP450. This metabolite is found in two tautomer forms, namely, 4-hydroxy-cyclophosphamide and aldophosphamide, which are mutually balanced. In the cells, aldophosphamide decays to acrolein and the cytotoxic agent phosphorus-amino mustard, which is a bifunctional alkylating agent. IFOS, as well as $\mathrm{CP}$, is inactive in vitro and is most likely activated in vivo in the liver by microsomal enzymes to 4-hydroxy-ifosfamide, which is in equilibrium with its tautomer aldoifosfamide. Aldo-phosfamide spontaneously decomposes to acrolein and the alkylation metabolite isofosfamide mustard.

Stenglova Netikova et $\mathrm{al}^{5}$ presented new data, which demonstrated the possibility of using titanium(IV) dioxide as a new, efficient, and cheap material for complete decontamination of anthracycline antibiotics. This pioneering study makes it attractive to scientists and a promising alternative way to perform cytostatics decontamination.

In this paper, we compared the previously used decontamination methodology of sodium hydroxide $(\mathrm{NaOH})$ and sodium hypochlorite $(\mathrm{NaClO})$ for $\mathrm{CP}$ and IFOS with the new procedure using a destructive sorbent base on nanocrystalline and nanodispersive titanium dioxide $\left(\mathrm{TiO}_{2}\right)$.

\section{Experimental}

All of the chemicals used, including titanium oxo-sulfate $\left(\mathrm{TiOSO}_{4}\right)$, urea $\left(\mathrm{CO}\left(\mathrm{NH}_{2}\right)_{2}\right), \mathrm{NaOH}, \mathrm{NaClO}$, and sulfuric acid $\left(\mathrm{H}_{2} \mathrm{SO}_{4}\right.$ ), were obtained from Sigma-Aldrich (St Louis, MO, USA), and CP and IFOS were obtained as drugs from the pharmaceutical company Sandoz (Holzkirchen, Germany). All the reagents used were analytical grade and employed without further purification; CP and IFOS were in pharmacological purity.

\section{Titania TITI5 sample preparation}

Homogeneous hydrolysis of titanium oxo-sulfate with urea was used to obtain titanium(IV) dioxide. This method is based on thermal decomposition of urea at a temperature higher than $60^{\circ} \mathrm{C}$. In a typical synthesis, ${ }^{5,6} 15 \mathrm{~g}$ of $\mathrm{TiOSO}_{4}$ was dissolved in $100 \mathrm{~mL}$ of hot distilled water acidified with $98 \% \mathrm{H}_{2} \mathrm{SO}_{4}$. The pellucid liquid was diluted into $4 \mathrm{~L}$ of distilled water and supplemented with $200 \mathrm{~g}$ of urea. The mixture was heated to $98^{\circ} \mathrm{C}$ with stirring for 6 hours until it reached a $\mathrm{pH}$ of 7.2. The formed precipitate was washed using decantation until the conductivity of $10 \mathrm{~S}$ was reached, filtered off, and dried at $105^{\circ} \mathrm{C}$.

\section{Characterization methods}

\section{Preparation of stock solutions}

For the stability testing, we prepared stock solutions of drugs in a variety of physiological solutions. The appropriate amount of drug injection solution in physiological solution was transferred to a $50 \mathrm{~mL}$ volumetric flask and filled to volume with physiological saline solution $0.9 \%$ sodium chloride $(\mathrm{NaCl})$ at a final concentration of $20 \mu \mathrm{g} / \mathrm{mL}$.

\section{Chromatographic conditions}

The concentrations of $\mathrm{CP}$ and IFOS were measured after adding $\mathrm{NaOH}(0.1 \mathrm{M})$ and $\mathrm{NaClO}(5 \%)$ by an isocratic high-performance liquid chromatography (HPLC) system of DIONEX UltiMate 3000 (Thermo Fisher Scientific, Waltham, MA, USA) consisting of a pump with a column of YMC Co. (Allentown, PA, USA; ODS Hydrosphere C18 150×4.6 mm ID) and a DAD detector with data-processing Chromeleon station software (Thermo Fisher Scientific). The UV detection of 5-FU was set at $230 \mathrm{~nm}$. Mobile phase A consisted of $0.1 \%$ formic acid in 100\% methanol, and mobile phase B consisted of $0.1 \%$ formic acid in Milli-Q water (5:95 v/v) at a flow rate of $0.500 \mathrm{~mL} / \mathrm{min}$. The column temperature was maintained at $30^{\circ} \mathrm{C}$. The injected volume of each sample was $20 \mu \mathrm{L}$. 
All samples after their degradation were analyzed by mass spectrometry (MS). The analysis of drugs was performed using an LTQ Orbitrap mass spectrometer (Thermo Fisher Scientific) following chromatographic separation using an HPLC system consisting of an autosampler and dual pumps. An HPLC system Thermo Finnigan (Thermo Fisher Scientific) was used. An LTQ Orbitrap MS equipped with an atmospheric pressure interface and an ESI ion source was used. The source voltage was set to $3.5 \mathrm{kV}$. The heated capillary temperature was maintained at $275^{\circ} \mathrm{C}$. Analyses were run using full MS (50-1,000 $\mathrm{m} / \mathrm{z}$ range) in the negative ion mode, with a resolution of 30,000 in ITMS mode.

The method was developed and validated with respect to linearity, accuracy, recovery, precision, system suitability, selectivity, and robustness, and forced degradation studies proved the stability indicating ability of the method.

Selectivity might include degradants and matrix. Decontamination studies were performed for cytotoxic drugs to provide an indication of the stability indicating property and selectivity of the proposed method. Intentional decomposition was attempted to stress conditions that were exposed to it with alkali $(0.01 \mathrm{M} \mathrm{NaOH})$ and sodium hypochlorite $(5 \% \mathrm{NaClO})$ to evaluate the ability of the proposed method for a decontamination strategy of cytotoxic drugs.

\section{Sampling procedure and analysis of the transformation products}

Decontamination tests were performed by using $\mathrm{CP}$ as internal standards. In this procedure, standards were mixed into the decontamination solution in a series of glass vials (Supelco [Bellefonte, PA, USA], $20 \mathrm{~mL}$ ). The vials were sealed with caps and covered with aluminum foil to protect the reaction mixture from sunlight. At predetermined time intervals $(0,5,15,20,30,50,70,90$, and 120 minutes $)$, the reaction was terminated by addition of formic acid $(0.1 \%)$. The solution was transferred to a smaller vial (Supelco, 2.0 $\mathrm{mL}$ ) and analyzed immediately by HPLC to determine oxidation or hydrolysis of the transformation products.

\section{HPLC method for the decomposition of cytostatics}

The decomposition of CP and IFOS on the reactive sorbents in water was measured at the University JE Purkyně in Ústí nad Labem using the methodology developed at the Institute of Inorganic Chemistry AVCR. ${ }^{5}$

\section{Fourier transform infrared spectroscopy analysis of cytostatics degradation}

The CP and IFOS degradation processes were studied on a Nicolet Impact 400D FTIR spectrometer (Nicolet CZ, s.r.o.,
Prague, Czech Republic) equipped with the Praying Mantis ${ }^{\mathrm{TM}}$ (Harrick, Pleasantville, NY, USA) for diffuse reflection measurements (DRIFTS). ${ }^{7}$

\section{Results and discussion}

As has already been discussed, nanocrystalline $\mathrm{TiO}_{2}$ prepared by homogeneous hydrolysis of oxo-titanium sulfate with urea was used for the degradation of CP and IFOS. According to the reaction conditions, $\mathrm{TiO}_{2}$ can be prepared either as an excellent photocatalytic pigment ${ }^{8-10}$ or as a destructive sorbent for stoichiometric decomposition of chemical warfare agents, ${ }^{6,11}$ pesticides, ${ }^{12}$ and some of the anthracycline antibiotic cytostatics. ${ }^{5}$

$\mathrm{CP}$ is the most commonly used alkylating agent (adding an alkyl group $\left[\mathrm{C}_{\mathrm{n}} \mathrm{H}_{2 \mathrm{n}+1}\right]$ to the DNA) in tumor therapy and represents a great contribution to stopping the proliferation of tumor cells, but there is also a health risk for medical staff. Cyclophosphamide is a "prodrug" in which the active chemotherapeutic is created in the liver.

LC-MS chromatogram and mass spectra of CP are presented in Figure S1; the chromatographic peak at retention time $t_{\mathrm{R}}=3.40$ minutes with $[\mathrm{M}+\mathrm{H}]^{+}=261.2\left(\mathrm{ESI}^{+}\right)$corresponds to pure $\mathrm{CP} .{ }^{13}$ The two reaction products are formed by the reaction of $\mathrm{CP}$ with $\mathrm{NaClO}$; after 5 minutes of reaction, it produced 4-hydroxy-cyclophosphamide $\left(t_{\mathrm{R}}=8.4\right.$ minutes, $\left.[\mathrm{M}+\mathrm{H}]^{+}=277.02\right)$, and after 15 minutes, it was identified as 3-(2-chloroethyl)-2-((2-chloroethyl)amino)-1,3,2-oxazaphosphinane 2-oxide, $\left(t_{\mathrm{R}}=6.50\right.$ minutes, $\left.[\mathrm{M}+\mathrm{H}]^{+}=261.09\right)$, also known under the name IFOS. LC chromatograms and the mass spectra of these reaction products are shown in Figure $\mathrm{S} 2$. The chromatographic behavior demonstrated that the 4-hydroxy-CP formed during the reaction with $\mathrm{NaClO}$ has a higher polarity than IFOS, which is indicated by a longer retention time. The reaction pathway of $\mathrm{CP}$ conversion in the presence of sodium hypochlorite is shown in Figure 1.

IFOS is similar to CP and is hydroxylated in cells to its active metabolite 4-hydroxy-ifosfamide and its tautomers form aldo-ifosfamide; by cleavage of acrolein, it changes from aldo-iphosphamide to iso-phosphorus-amino mustard.

The main active human metabolite of $\mathrm{CP}$ is 4-hydroxycyclophosphamide, and its formation occurs through hydroxylation. ${ }^{14}$ IFOS is a chemotherapeutic agent chemically related to the nitrogen mustards and a synthetic analog of CP. Trisse ${ }^{15}$ reported that IFOS is chemically stable in $\mathrm{NaCl}(0.9 \%)$. We expect that it will also be stable in sodium hypochlorite $\mathrm{NaClO}(5 \%)$, because no other reaction product has been detected. 


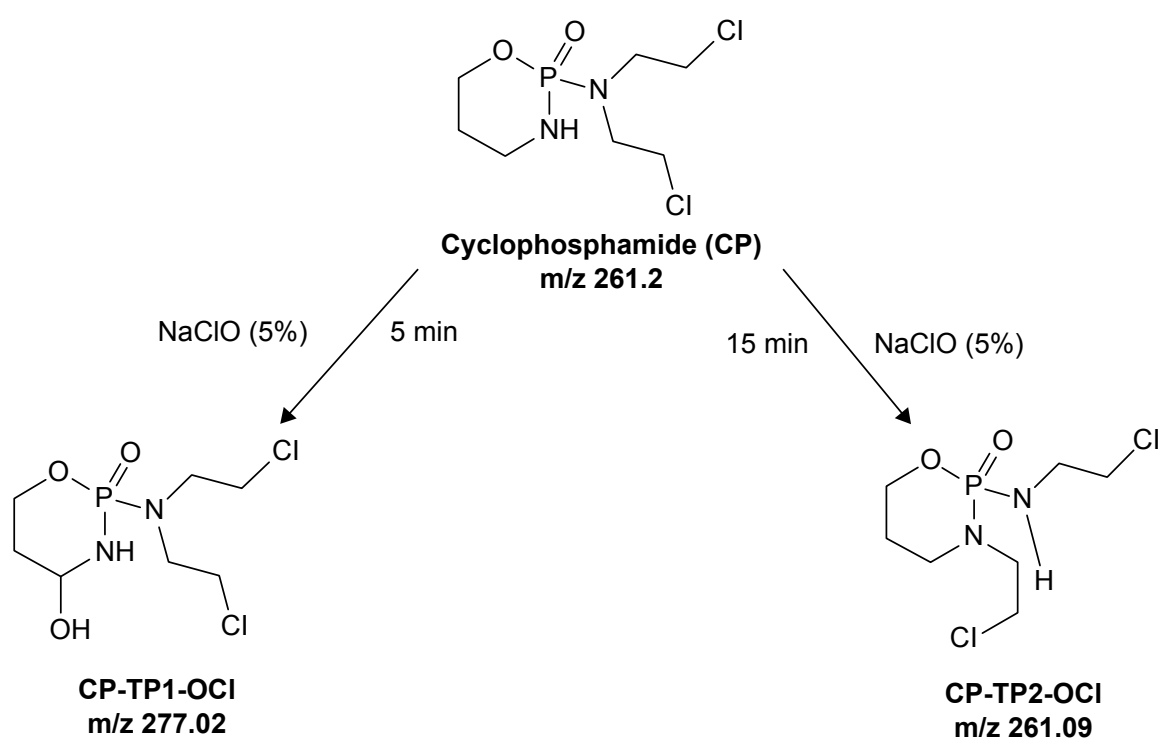

Figure I The pathway of conversion of $\mathrm{CP}$ in the presence of sodium hypochlorite ( $5 \%$ solution). Abbreviations: CP, cyclophosphamide; CP-TPI-OCl, 4-hydroxy-cyclophosphamide; CP-TP2-OCl, ifosfamide.

The appearance of new peaks during the decontamination process of $\mathrm{CP}$ in $5 \% \mathrm{NaClO}$ aqueous solution is indicative of the formation of decay products.

$\mathrm{CP}$ reacts with aqueous solutions of $0.01 \mathrm{M} \mathrm{NaOH}$, and after 15 minutes, the reaction produces 3-((amino(bis $(2-$ chloroethyl)amino)phosphoryl)oxy) propanoic acid $\left(t_{\mathrm{R}}=7.49\right.$ minutes, $\left.[\mathrm{M}+\mathrm{H}]^{+}=293.02\right)$, which is also the end product. It is formed by the opening cycle of the $\mathrm{CP}$ backbone leading to the formation of carboxyl $(-\mathrm{COOH})$ and amino $(-\mathrm{NH} 2)$ groups. The scheme of reaction of $0.01 \mathrm{M} \mathrm{NaOH}$ with CP is presented in Figure 2. HPLC-MS chromatogram and the mass spectra of transformation product $3-(($ amino(bis (2-chloroethyl)amino)phosphoryl)oxy) propanoic acid of $\mathrm{CP}$ are presented in Figure S3.

The results of the adsorption/degradation experiments in the presence of $\mathrm{TiO}_{2}$ indicated that no adsorption product occurred throughout the 60-minute reaction time in an aqueous medium. In the case of adsorption/degradation of $\mathrm{CP}$ on the surface of $\mathrm{TiO}_{2}$, we can explain that based on the knowledge of the stoichiometric degradation of organophosphates, which are decomposed bimolecular nucleophilic substitution $\mathrm{S}_{\mathrm{N}}^{2}$ mechanisms, where surface $-\mathrm{OH}$ groups, in

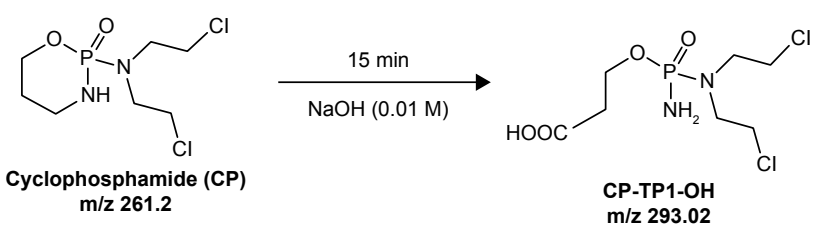

Figure 2 Scheme of degradation $\mathrm{CP}$ after reaction with a solution of $0.01 \mathrm{M}$ $\mathrm{NaOH}$.

Abbreviations: CP, cyclophosphamide; CP-TPI-OH, 3-((amino(bis(2-chloroethyl) amino)phosphoryl)oxy) propanoic acid. this case, act as a strong nucleophile, as we have reported in our previous studies. ${ }^{16,17}$ The electrophilic center nitrogen atom in the drug molecule will probably play a crucial role in the adsorption process. In the first part, the electron from the center nitrogen atom travels to the inside of the molecule. The mechanism is known as "inner sphere electron transfer"18,19 with elimination of a molecule of $\mathrm{HCl}$. The mechanism is next followed by a substitution reaction to "temporarily" affect the electrophilic nitrogen atom (denoted as +). The final step is the creation of a stable surface complex. This can be explained by an increased number of catalyst active sites that are available for the adsorption reaction..$^{20,21}$ The proposed mechanism of adsorption of $\mathrm{CP}$ on a titania surface is shown in Figure 3. Kinetics of the reaction of $\mathrm{CP}$ with $5 \%$ solution $\mathrm{NaClO}$ and $0.01 \mathrm{M} \mathrm{NaOH}$ are presented in Figure $4 \mathrm{~A}$ and $\mathrm{B}$ (blue curve). The origin and degradation of transformation products denoted as CP-TP1 (4-hydroxy-cyclophosphamide) shows a red curve and transformation products denoted as CP-TP2 (IFOS) in a green curve. It is clear that $\mathrm{CP}$ is not completely degraded after 120 minutes, and after reaction with sodium hydroxide, the reaction product is another cytotoxic agent, IFOS. CP in the presence of nanostructured $\mathrm{TiO}_{2}$ is adsorbed and gradually degraded without the formation of reaction products. The kinetics of CP degradation were calculated as first-order kinetics [odkaz], and are $k=0.0602 \mathrm{~min}^{-1}$ and the degree of conversion is $89.7 \%$ at 120 minutes (Figure 4C).

Since IFOS $(\mathrm{m} / \mathrm{z} 261.09)$ was identified as one of the transformation products (CP-TP2-ClO) of CP in the $\mathrm{NaClO}(5 \%)$ agent, it was also in this case tested for its stability in both decontamination agents $(\mathrm{NaClO}$ and $\mathrm{NaOH})$. The typi- 
Cyclophosphamide (CP)

Nucleophilic substitution

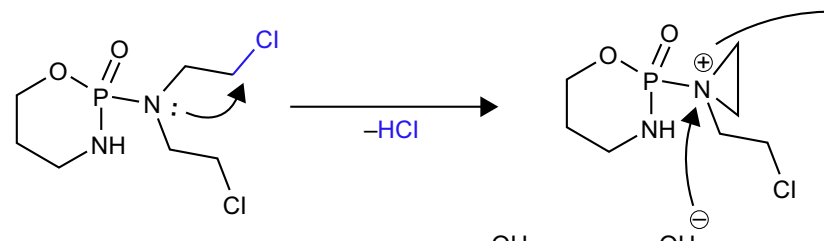

$261.2 \mathrm{~m} / \mathrm{z}$

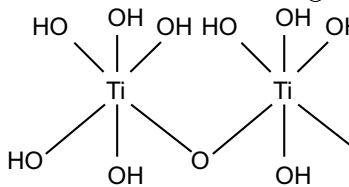

$\mathrm{OH}$

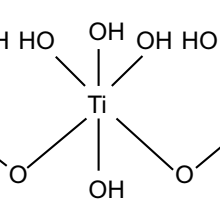

Titania surface layer<smiles>COCCN(CCCl)P1(=O)NCCCO1</smiles>

\section{Adsorption on titania surface}<smiles>CP(C)(O)(O)OCO</smiles>
$\mathrm{OH} \mathrm{HO} \mathrm{OH} \mathrm{OH}$<smiles>C[Te](C)(O)O[Te](O)(O)(O)(O)O</smiles>

Figure 3 The proposed mechanism of adsorption of $\mathrm{CP}$ on a titania surface. Abbreviation: $\mathrm{CP}$, cyclophosphamide.

cal LC-MS chromatogram and mass spectra of IFOS $\left(t_{\mathrm{R}}=6.50\right.$ minutes, $[\mathrm{M}+\mathrm{H}]^{+}=261.09$ ) are presented in Figure S4. After the reaction with sodium hydroxide $(\mathrm{NaOH}, 0.01 \mathrm{M})$ the agent has had identified only one transformation product formed by alkylation of IFOS after 30 minutes as ifosforamide mustard (known as palifosfamide). ${ }^{22}$ This transformation product is labeled IFOS-TP1-OH $\left(t_{\mathrm{R}}=2.49\right.$ minutes, $\left.[\mathrm{M}+\mathrm{H}]^{+}=219.99\right)$. The LC-MS chromatogram and mass spectra of the transformation product IFOS-TP1-OH of IFOS in sodium hydroxide (NaOH 0.01 M agent) are shown in Figure S5.
A

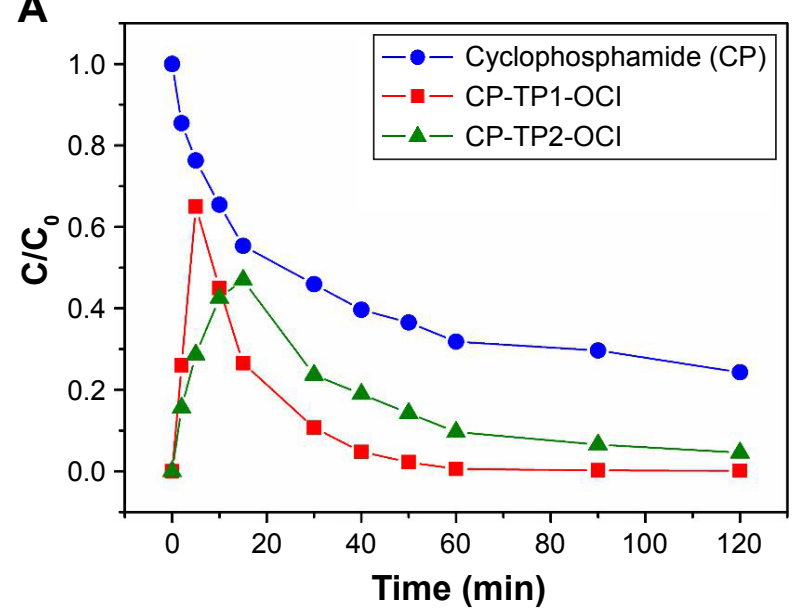

B

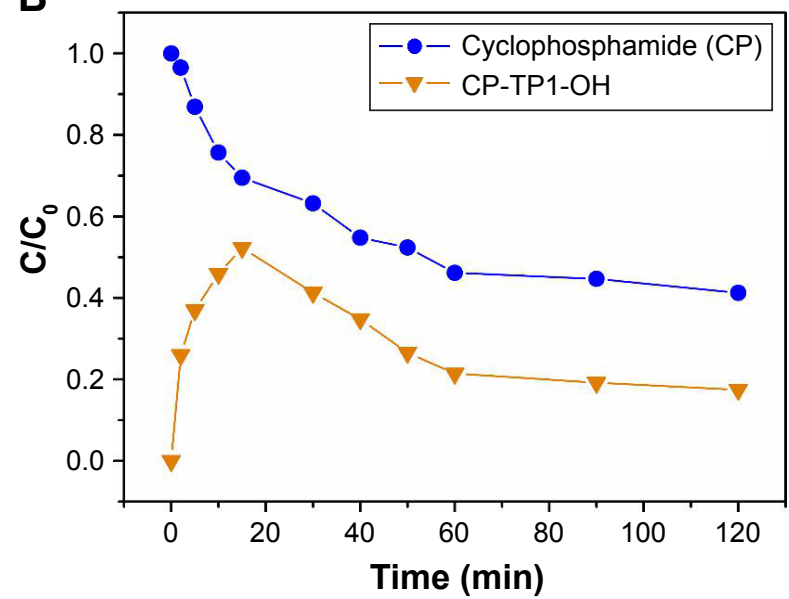

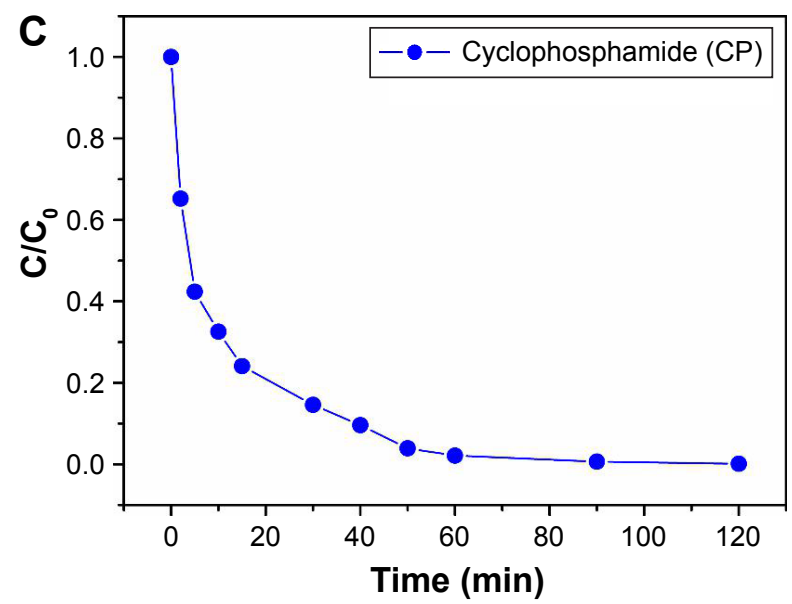

Figure 4 Transformation products formed during CP degradation plotted as a function of the normalized concentration (C/C $)$ of cyclophosphamide decay. Note: Transformation products formed during the decontamination time (minutes) in the presence of $(\mathbf{A}) 5 \% \mathrm{NaClO}$ agent, (B) $0.0 \mathrm{I} \mathrm{M} \mathrm{NaOH}$ agent, and (C) $\mathrm{TiO}_{2}$. Abbreviations: CP, cyclophosphamide; CP-TPI-OCI, 4-hydroxy-cyclophosphamide; CP-TP2-OCl, ifosfamide. 


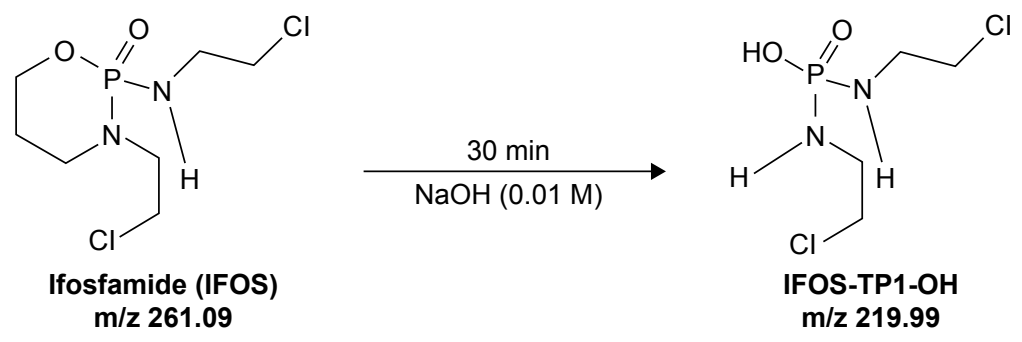

Figure 5 The proposed pathway of conversion of IFOS in the presence of a sodium hydroxide (0.0I M) agent. Abbreviations: IFOS, ifosfamide; IFOS-TPI-OH, ifosforamide mustard.

Kaijser et $\mathrm{al}^{23}$ described a sensitive and selective method for the analysis of ifosforamide mustard in plasma. The method consists of direct derivatization of ifosforamide mustard in plasma with diethyldithiocarbamate and subsequent solid-phase extraction of the resulting derivative. The analysis of the derivatization product was performed by HPLC with UV detection (HPLC-UV). ${ }^{23}$ Ifosforamide mustard probably represents the most important cytotoxic compound able to produce irreversible cross-links between DNA strands. In tumor cells, ifosforamide mustard reacts with DNA, causing cell death. ${ }^{24}$ The scheme of IFOS degradation in the presence of $0.01 \mathrm{M}$ $\mathrm{NaOH}$ is shown in Figure 5. The sodium hypochlorite agent $(5 \%)$ did not result in any identified transformation product.

In the case of IFOS degradation on the surface of $\mathrm{TiO}_{2}$, only one oxidation product, 4-hydroxyifosfamide $\left(\mathrm{C}_{7} \mathrm{H}_{15} \mathrm{Cl}_{2} \mathrm{~N}_{2} \mathrm{O}_{3} \mathrm{P}\right)$, was identified after 15 minutes of reaction time $\left([\mathrm{M}+\mathrm{H}]^{+}=276.09\right)$. Figure 6 presents the proposed pathway of adsorption of IFOS on a titania surface.

This degradation product is a metabolic product of IFOS, which is formed by hydroxylation at the ring carbon atom 4 to form the unstable intermediate 4-hydroxyifosfamide. This metabolite then rapidly degrades to the stable urinary metabolite 4-ketoifosfamide. The stable urinary metabolite, 4-carboxyifosfamide, is formed upon opening of the ring. These metabolites have not been found in obtained solutions after the adsorption reaction with $\mathrm{TiO}_{2}{ }^{25}$ The kinetics of the reaction of IFOS (violet curve) with the solution of $5 \%$ $\mathrm{NaClO}$ and $0.01 \mathrm{M} \mathrm{NaOH}$ are presented in Figure $7 \mathrm{~A}$ and $\mathrm{B}$. The green curve in Figure 7B shows the origin of the transformation products named IFOS-TP1-OH and ifosforamide mustard. Titanium dioxide mineralized IFOS and transformed 4-hydroxyifosmamide into phosphoric acid, carbon dioxide, and water. The rate constant $k$ and degree of conversion $d$ are $0.0746 \mathrm{~min}^{-1}$ and $96.5 \%$, respectively (Figure 7C).

Significant degradation pathways of both agents, CP and IFOS, derived from mustard gas $^{26}$ as well as their degradation products were detected on the surface by in situ sensing DRIFT spectra in reaction time. ${ }^{27}$ DRIFT spectral data provide evidence of the chemical interactions with a titania surface. The results of the degradation experiments in the heterogeneous $\mathrm{CP}$-water- $\mathrm{TiO}_{2}$ system indicated that no degradation product occurred throughout the 120 minutes reaction time in an aqueous medium.

However, from the DRIFT spectra obtained in the reaction time for the $\mathrm{CP}-\mathrm{TiO}_{2}$ system there are some important bands recognizable from surface-adsorbed $\mathrm{CP}$. The surface

\section{Ifosfamide (IFOS)}

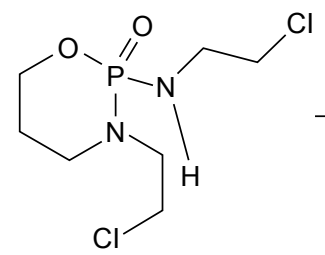

$261.09 \mathrm{~m} / \mathrm{z}$

\section{Adsorption on titania surface}

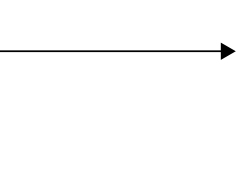

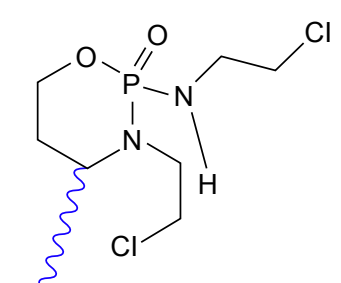
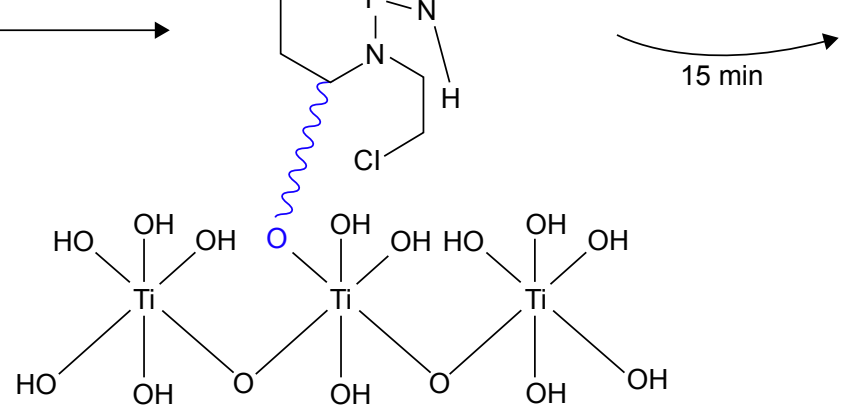

Titania surface layer
4-Hydroxyifosfamide

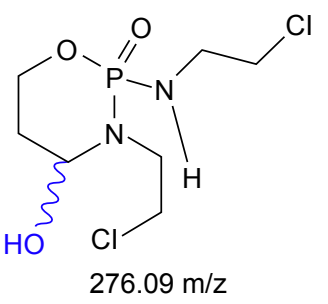

Figure 6 The proposed pathway of adsorption of IFOS on a titania surface.

Abbreviation: IFOS, ifosfamide. 
A

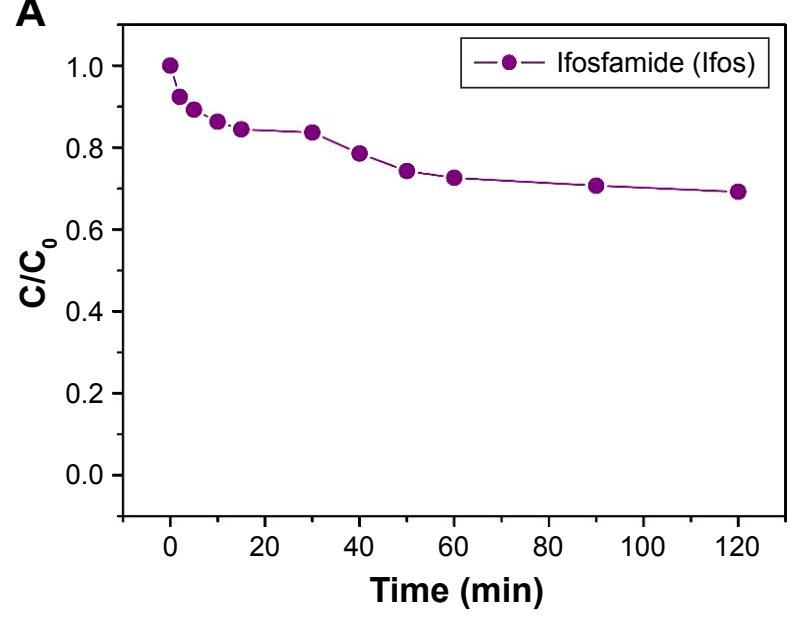

B

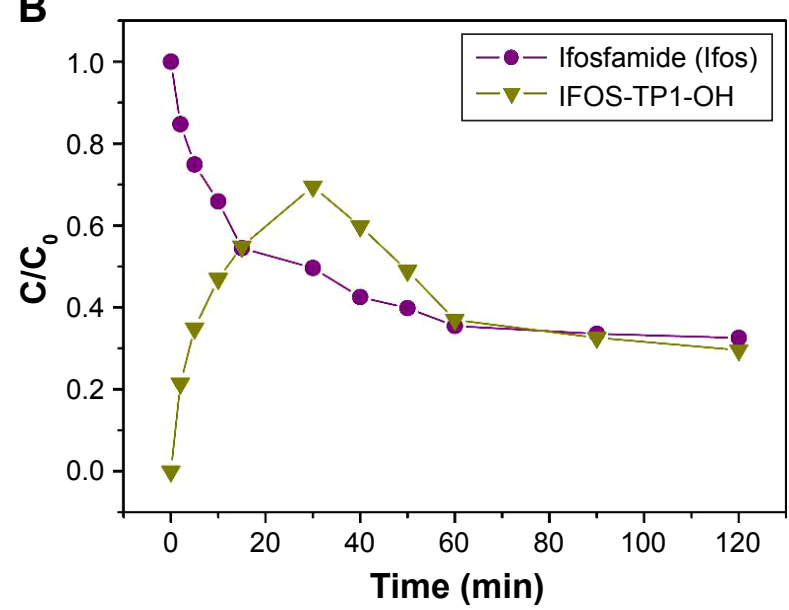

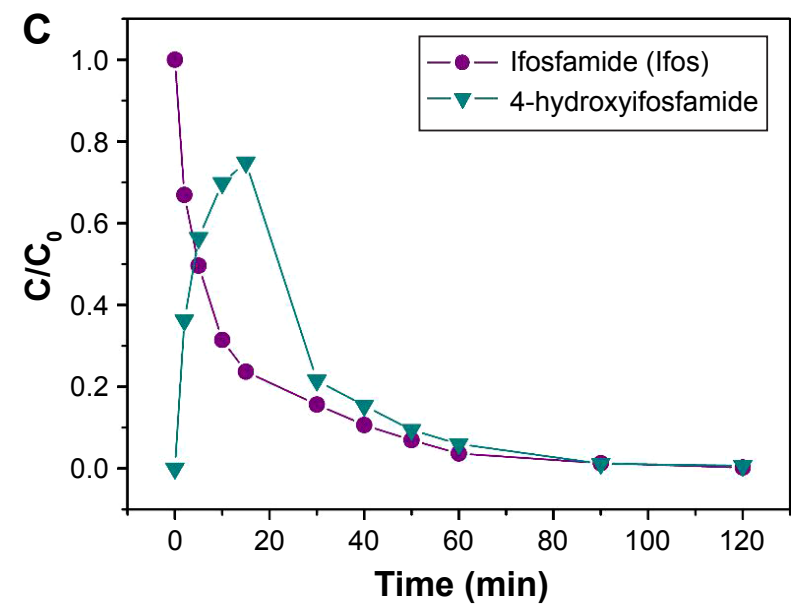

Figure 7 Transformation products formed during IFOS degradation plotted as a function of the normalized concentration (C/C $)$ of IFOS decay.

Note: Transformation products formed during the decontamination time (minutes) in the presence of $(\mathbf{A}) 5 \% \mathrm{NaClO}$ agent, $(\mathbf{B}) 0.0 \mathrm{I} \mathrm{M} \mathrm{NaOH}$ agent, and $(\mathbf{C}) \mathrm{TiO}_{2}$. Abbreviations: IFOS, ifosfamide; IFOS-TPI-OH, ifosforamide mustard.

degradation of $\mathrm{CP}$ is realized through binding of the electrophilic phosphoryl oxygen $v(\mathrm{P}=\mathrm{O})$ to the surface hydroxyl groups by hydrogen-bond formation. The $\mathrm{P}=\mathrm{O}$ bond $(\sim 1,280$ $\left.1,305 \mathrm{~cm}^{-1}\right)$ is shifted to a lower wave number $\left(\sim 1,215 \mathrm{~cm}^{-1}\right)$, which may indicate the decay of this group during stable surface complex formation with surface hydroxyls. ${ }^{7,27}$ As can be further seen, the vibrational band around a wave number of $1,170 \mathrm{~cm}^{-1}$ corresponding to $\mathrm{v}(\mathrm{P}-\mathrm{O})$ vibration absorption is lost over time. It has been demonstrated that the ring in the molecules was completely opened by cleavage of the $\mathrm{P}-\mathrm{O}$ bond. On the other hand, vibration bands at 1,030-1,058 $\mathrm{cm}^{-1}$, which can be assigned to a specific vibration $\mathrm{v}(\mathrm{P}-\mathrm{O}-\mathrm{C})$, remain unchanged, only showing a slight deformation due to the separation of the electronegative oxygen from the phosphorus in the ring. ${ }^{28}$ Therefore, it is apparent that other vibration bands will be influenced. The peaks at 922 and $1,455-1,460 \mathrm{~cm}^{-1}$ are the absorptions of $\mathrm{v}(\mathrm{P}-\mathrm{N})$, and the peaks at $968,2,850$, and $2,960 \mathrm{~cm}^{-1}$ are the absorptions of $v(\mathrm{C}-\mathrm{H})$ stretching vibrations. ${ }^{29,30}$ In the DRIFT spectra of CP

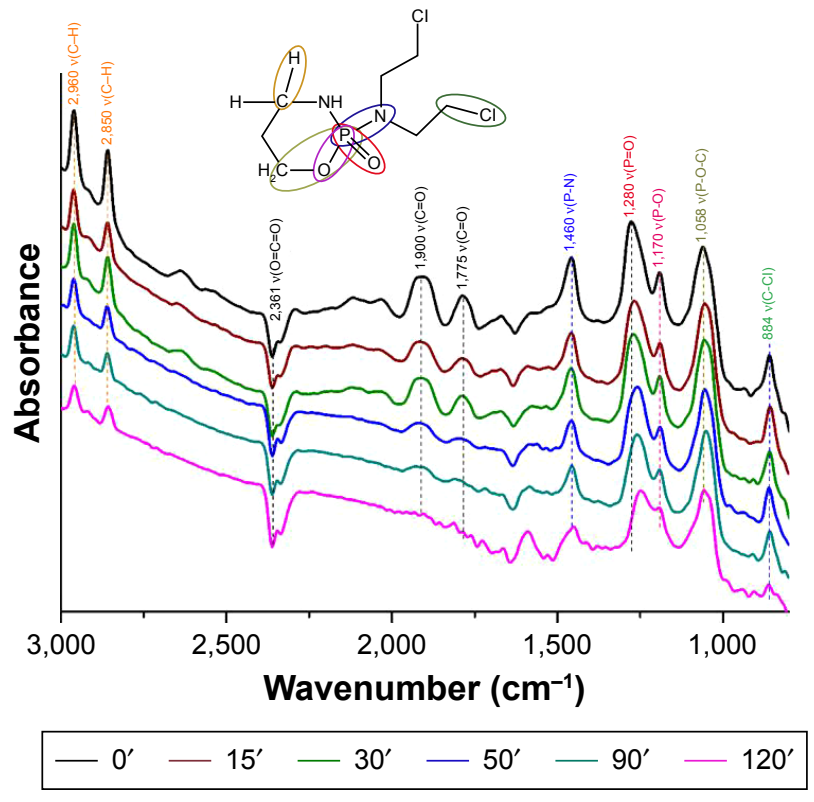

Figure 8 The DRIFTS fingerprint spectra of CP destructive adsorption on the titanium oxide.

Abbreviations: CP, cyclophosphamide; DRIFTS, diffuse reflectance infrared Fourier transform spectroscopy. 


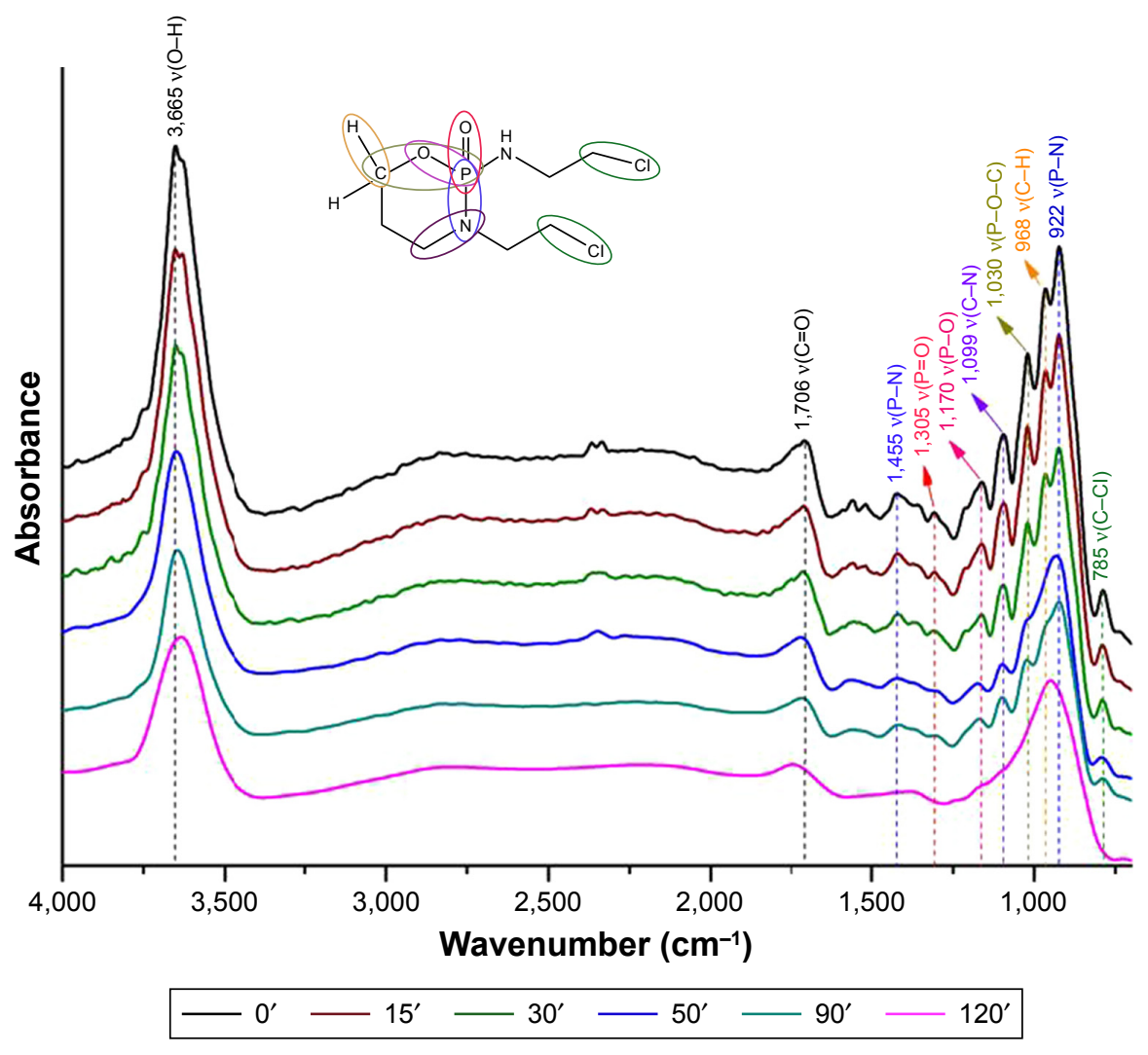

Figure 9 The DRIFTS fingerprint spectra of IFOS destructive adsorption on the titanium oxide.

Abbreviations: IFOS, ifosfamide; DRIFTS, diffuse reflectance infrared Fourier transform spectroscopy.

and IFOS are the characteristic peaks at 785 and $884 \mathrm{~cm}^{-1}$, respectively, corresponding to the $v(\mathrm{C}-\mathrm{Cl})$ bond, which slowly decreases due to the dehydrohalogenation pathway, where the Ti(IV) centers act as Lewis acids and promote the cleavage of the labile $\mathrm{C}-\mathrm{Cl}$ bond in the drug molecule (the mechanism is known as "inner sphere electron transfer") accompanied by elimination of a molecule of $\mathrm{HCl}^{31}$

In the case of IFOS degradation, we assume two different reaction pathways in aqueous solution (heterogeneous IFOS-water- $\mathrm{TiO}_{2}$ system) and the surface interaction of pure IFOS (IFOS- $-\mathrm{TiO}_{2}$ system). In the first step, IFOS is superficially oxidized to 4-hydroxyifosfamide (4-H-IFOS) as the major degradation product identified after 5 minutes in the retention time of 5.213 minutes with $m / z[\mathrm{M}+\mathrm{H}]^{+}=276.09$ (faster process) followed by the opening of the agent cycle by cleavage of the $\mathrm{P}-\mathrm{O}$ bond similarly to what occurs with $\mathrm{CP}$ (a slower process). This metabolite has not yet been found in the obtained solution after the adsorption reaction with $\mathrm{TiO}_{2}{ }^{32}$ Other DRIFT band characteristics remain similar to CP. Nevertheless, in all cases, the belt vibration intensity of the bands is reduced due to further cleavage of the molecules into smaller fragments, which apparently remain on the surface. In the presence of gaseous $\mathrm{CO}_{2(\mathrm{~g})}$, absorption bands appear at $1,706,1,775$, and $1,900 \mathrm{~cm}^{-1}$, corresponding to the carbonyl group $v(\mathrm{C}=\mathrm{O})$. The band at $2,361 \mathrm{~cm}^{-1}$ is assigned to adsorbed $\mathrm{CO}_{2}$ with a Ti-O-C-O adsorption configuration. ${ }^{33}$

The examples of the fingerprint DRIFT spectra $\left(700-4,000 \mathrm{~cm}^{-1}\right)$ obtained at preselected time intervals $(0,15,30,50,90$, and 120 minutes) after reactive adsorption on the titanium oxide denoted TIT15 are presented in Figures 8 and 9. The proposed mechanism pathways of adsorption of $\mathrm{CP}$ and IFOS on the titania surface are shown in Figures 10 and 11.

\section{Conclusion}

Aqueous solutions of sodium hydroxide and sodium hypochlorite have been used as cleaner simulants in medical facilities for the remediation of cytostatics from the family of nitrogen mustards. Sodium hydroxide decomposes CP to 3-((amino(bis(2-chloroethyl)amino)phosphoryl)oxy) propanoic acid and sodium hypochlorite forms two reaction products, namely, IFOS and 4-hydroxy-cyclophosphamide. IFOS is stable in a solution of sodium hypochlorite; IFOS in the presence of sodium hydroxide is converted to toxic IFOS mustard. In contrast, a destructive sorbent based on nanocrystalline and nanodispersive $\mathrm{TiO}_{2}$ can on its surface stoichiometrically decompose $\mathrm{CP}$ and IFOS respectively, into a nontoxic reaction product (fragments) and then mineralize 


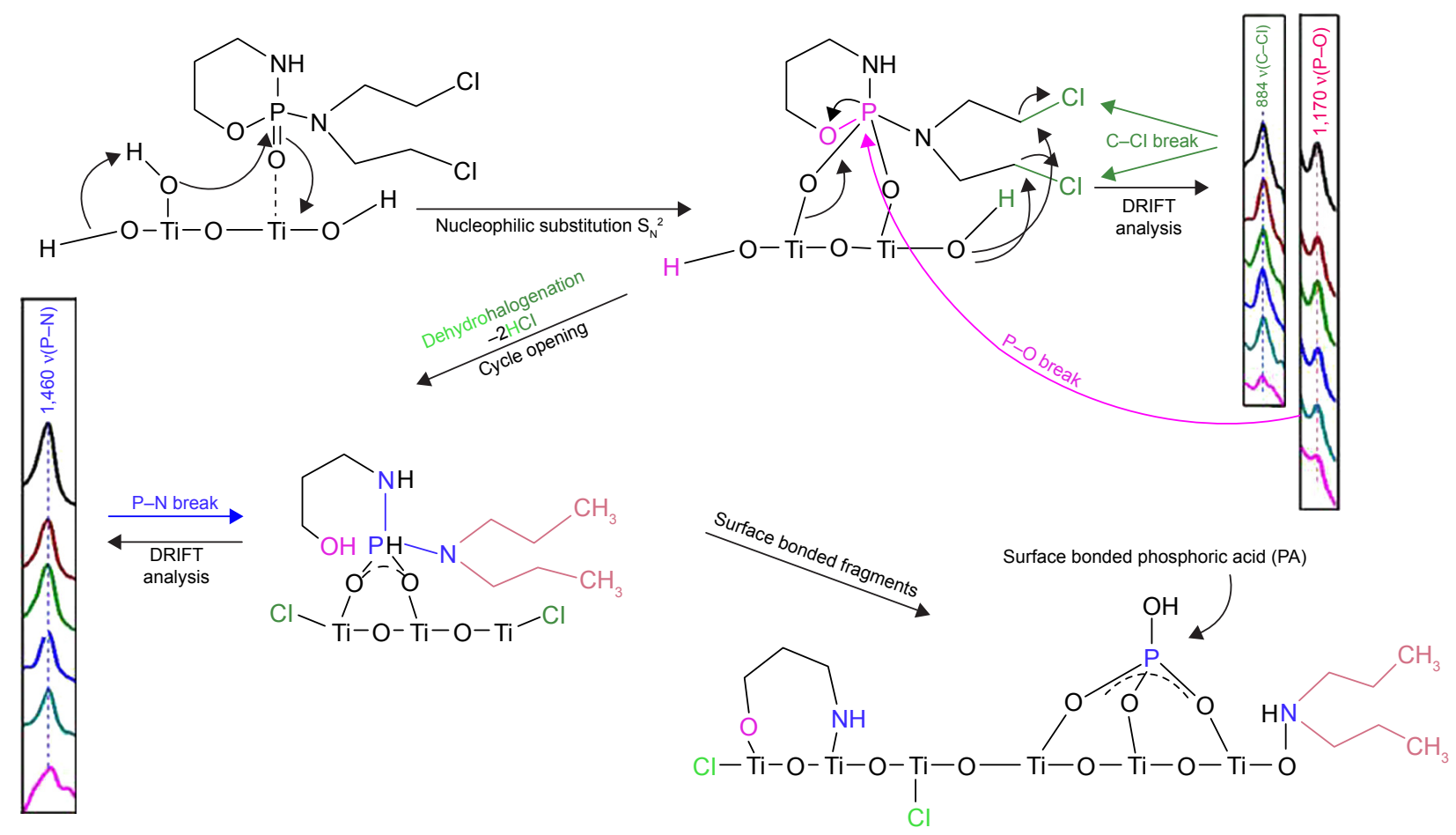

Figure 10 The proposed mechanistic pathway of reactive adsorption of $C P$ on a titania surface with DRIFT characteristics. Abbreviation: $\mathrm{CP}$, cyclophosphamide.

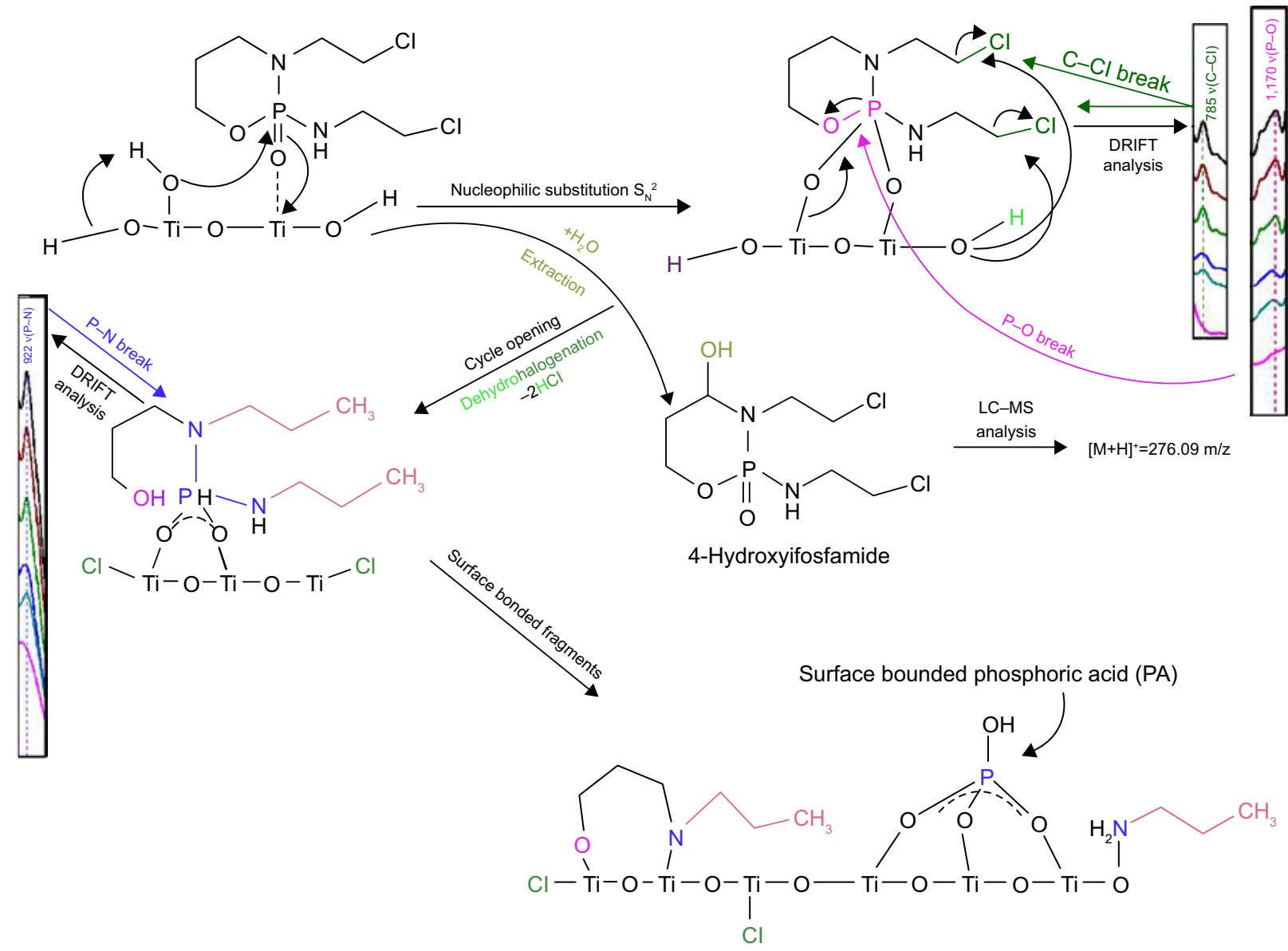

Figure II The proposed mechanistic pathway of reactive adsorption of IFOS on a titania surface with DRIFT characteristics. Abbreviation: IFOS, ifosfamide. 
them to water and carbon dioxide. Nanodispersive $\mathrm{TiO}_{2}$ is an effective degradation agent for decontamination of surfaces from cytostatics in medical facilities.

\section{Disclosure}

The authors report no conflicts of interest in this work.

\section{References}

1. Wagner GW, Bartram PW, Vx KKJ. GD and HD reactions with nanosize particles. Abstracts of Papers of the American Chemical Society. 1999;217:3225-3228.

2. Stengl V, Henych J, Janos P, Skoumal M. Nanostructured metal oxides for stoichiometric degradation of chemical warfare agents. In: DeVoogt P, editor. Reviews of Environmental Contamination and Toxicology. Vol 236. Berlin: Springer; 2016:239-258.

3. Gilman A. The initial clinical trial of nitrogen mustard. Am J Surg. 1963;105(5):574-578.

4. Hirsch J. An anniversary for cancer chemotherapy. JAMA. 2006; 296(12):1518-1520.

5. Stenglova Netikova IR, Slusna M, Tolasz J, St'astny M, Popelka S, Stengl V. A new possible way of anthracycline cytostatics decontamination. New J Chem. 2017;41:3975-3985.

6. Štengl V, Maříková M, Bakardjieva S, Šubrt J, Opluštil F, Olšanská M. Reaction of sulfur mustard gas, soman and agent VX with nanosized anatase TiO2 and ferrihydrite. J Chem Technol Biotechnol. 2005; 80(7):754-758.

7. Šteng1 V, Henych J, Grygar T, Pérez R. Chemical degradation of trimethyl phosphate as surrogate for organo-phosporus pesticides on nanostructured metal oxides. Mater Res Bull. 2015;61:259-269.

8. Bakardjieva S, Šubrt J, Štengl V, Dianez MJ, Sayagues MJ. Photoactivity of anatase-rutile $\mathrm{TiO} 2$ nanocrystalline mixtures obtained by heat treatment of homogeneously precipitated anatase. Appl Catal B. 2005;58(3-4):193-202.

9. Štengl V, Bakardjieva S, Murafa N, Houšková V, Lang K. Visiblelight photocatalytic activity of $\mathrm{TiO}_{2} / \mathrm{ZnS}$ nanocomposites prepared by homogeneous hydrolysis. Microporous and Mesoporous Materials. 2008;110(2-3):370-378.

10. Štengl V, Bakardjieva S, Murafa N. Preparation and photocatalytic activity of rare earth doped $\mathrm{TiO}_{2}$ nanoparticles. Mater Chem Phys. 2009; 114(1):217-226.

11. Stengl V, Grygar TM, Opluštil F, Němec T. Ge4+ doped $\mathrm{TiO}_{2}$ for stoichiometric degradation of warfare agents. J Hazard Mater. 2012; 227-228:62-67.

12. Henych J, Štengl V, Slušná M, et al. Degradation of organophosphorus pesticide parathion methyl on nanostructured titania-iron mixed oxides. Appl Surf Sci. 2015;344:9-16.

13. Santana-Viera S, Guedes-Alonso R, Sosa-Ferrera Z, SantanaRodríguez JJ, Kabir A, Furton KG. Optimization and application of fabric phase sorptive extraction coupled to ultra-high performance liquid chromatography tandem mass spectrometry for the determination of cytostatic drug residues in environmental waters. J Chromatogr A. 2017;1529:39-49.

14. Baumann F, Preiss R. Cyclophosphamide and related anticancer drugs. J Chromatogr B Biomed Sci Appl. 2001;764(1-2):173-192.

15. Trissel LA. The Handbook on Injectable Drugs: Single User Version. Bethesda, MD: American Society of Health-System Pharmacists; 2011.
16. Janos P, Kuran P, Kormunda M, et al. Cerium dioxide as a new reactive sorbent for fast degradation of parathion methyl and some other organophosphates. J Rare Earths. 2014;32(4):360-370.

17. Št’astný M, Štengl V, Henych J, Tolasz J, Vomáčka P, Ederer J. Mesoporous manganese oxide for the degradation of organophosphates pesticides. J Mater Sci. 2016;51(5):2634-2642.

18. Matyjaszewski K. Inner sphere and outer sphere electron transfer reactions in atom transfer radical polymerization. Macromol Symp. 1998;134(1):105-118.

19. Jeon J, Goddard WA, Kim H. Inner-sphere electron-transfer single iodide mechanism for dye regeneration in dye-sensitized solar cells. $J$ Am Chem Soc. 2013;135(7):2431-2434.

20. Maier WF. Transition Metal Oxides: Surface Chemistry and Catalysis. (Reihe: Studies in Surface Science and Catalysis, Vol. 45). Von H. H. Kung. Elsevier, Amsterdam 1989. X, 282 S., geb. HFl. 215.00. - ISBN 0-444-87394-5. Angew Chem Int Ed Engl. 1990;102(8):965-966.

21. Gq L, Linsebigler A, Yates JT. Ti3+ Defect Sites on $\mathrm{TiO}_{2}(110)-$ Production and Chemical Detection of Aactive Sites. J Phys Chem. 1994;98(45):11733-11738.

22. Nicolao P, Giometto B. Neurological toxicity of ifosfamide. Oncology. 2003;65(Suppl 2):11-16.

23. Kaijser GP, Beijnen JH, Rozendom E, Bult A, Underberg WJ. Analysis of ifosforamide mustard, the active metabolite of ifosfamide, in plasma. J Chromatogr B Biomed Appl. 1996;686(2):249-255.

24. Furlanut M, Franceschi L. Pharmacology of ifosfamide. Oncology. 2003;65(Suppl 2):2-6.

25. Fleming RA. An overview of cyclophosphamide and ifosfamide pharmacology. Pharmacotherapy. 1997;17(5):S146-S154.

26. Goodman LS, Wintrobe MM, Dameshek W, Goodman MJ, Gilman A, Mclennan MT. Nitrogen-mustard therapy - use of methyl-bis(betachloroethyl)amine hydrochloride and tris(beta-chloroethyl)amine hydrochloride for hodgkins-disease, lymphosarcoma, leukemia and certain allied and miscellaneous disorders (Reprinted). JAMA. 1984; 251(17):2255-2261.

27. Henych J, Janoš P, Kormunda M, Tolasz J, Stengl V. Reactive adsorption of toxic organophosphates parathion methyl and DMMP on nanostructured Ti/Ce oxides and their composites. Arabian Journal of Chemistry. Epub 11 June 2016.

28. Paci A, Martens T, Royer J. Anodic oxidation of ifosfamide and cyclophosphamide: a biomimetic metabolism model of the oxazaphosphorinane anticancer drugs. Bioorg Med Chem Lett. 2001;11(10): 1347-1349.

29. Wen Z, Jincheng W. Preparation and Characterization of a Cyclophosphamide-Core PAMAM Dendritic Montmorillonite. Silicon. 2018;10(2):483-493.

30. James C, Ravikumar C, Sundius T, et al. FT-Raman and FTIR spectra, normal coordinate analysis and ab initio computations of (2-methylphenoxy)acetic acid dimer. Vib Spectrosc. 2008;47(1): $10-20$.

31. Arcibar-Orozco JA, Panettieri S, Bandosz TJ. Reactive adsorption of CEES on iron oxyhydroxide/(N-)graphite oxide composites under visible light exposure. J Mater Chem A Mater. 2015;3(33):17080-17090.

32. Fleming RA. An overview of cyclophosphamide and ifosfamide pharmacology. Pharmacotherapy. 1997;17(5 Pt 2):146s-154s.

33. Liao L-F, Lien C-F, Shieh D-L, Chen M-T, Lin J-L. FTIR Study of Adsorption and Photoassisted Oxygen Isotopic Exchange of Carbon Monoxide, Carbon Dioxide, Carbonate, and Formate on $\mathrm{TiO}_{2}$.J Phys Chem B. 2002;106(43):11240-11245. 


\section{Supplementary materials}
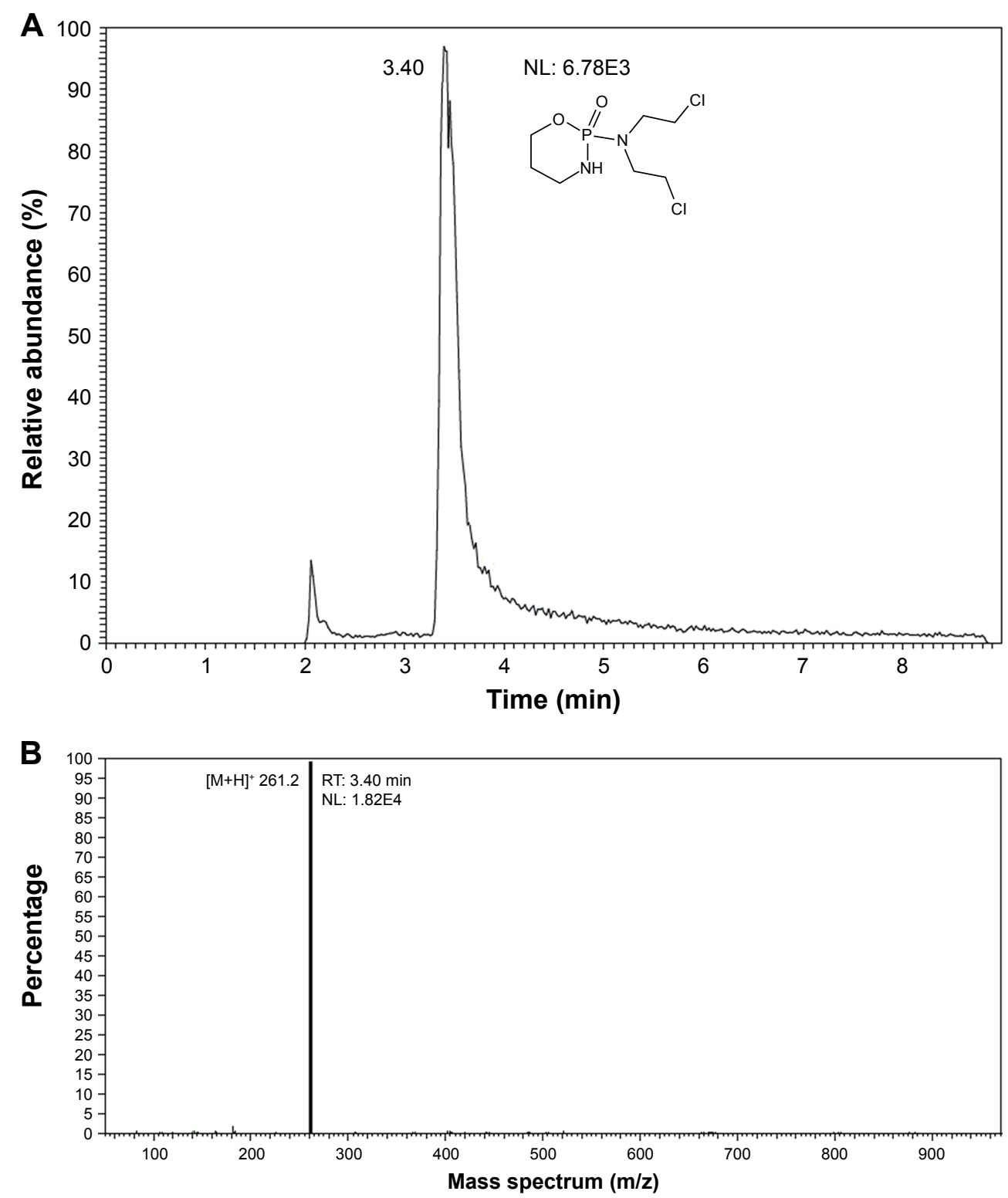

Figure SI HPLC-MS chromatogram (A) and mass spectra (B) of CP.

Note: Adduction is represented by $[\mathrm{M}+\mathrm{H}]+$, formed by the interaction of a molecule with a proton (hydron).

Abbreviations: CP, cyclophosphamide; HPLC-MS, high-performance liquid chromatography-mass spectrometry; NL, intensity of the signal; RT, retention time. 

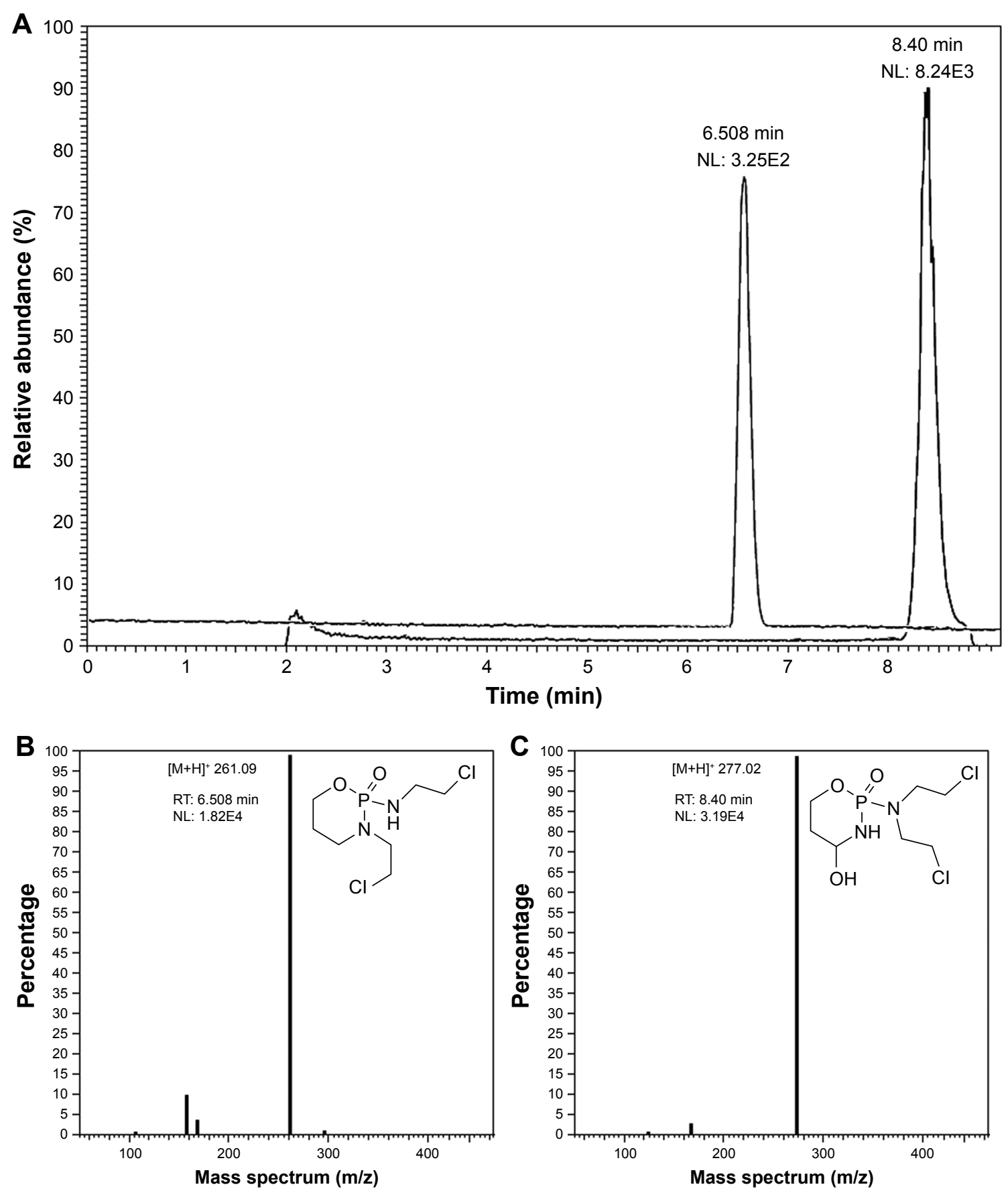

Figure S2 HPLC-MS chromatogram (A) and mass spectra of the transformation product of CP (B) 4-hydroxycyclophosphamide and (C) 3-(2-chloroethyl)-2-((2-chloroethyl) amino)-1,3,2-oxazaphosphinane 2-oxide (IFOS) from $\mathrm{CP}$ in sodium hypochlorite $5 \%$ solution ( $\mathrm{NaClO}$ ).

Note: Adduction is represented by $[\mathrm{M}+\mathrm{H}]+$, formed by the interaction of a molecule with a proton (hydron).

Abbreviations: CP, cyclophosphamide; HPLC-MS, high-performance liquid chromatography-mass spectrometry; NL, intensity of the signal; RT, retention time. 

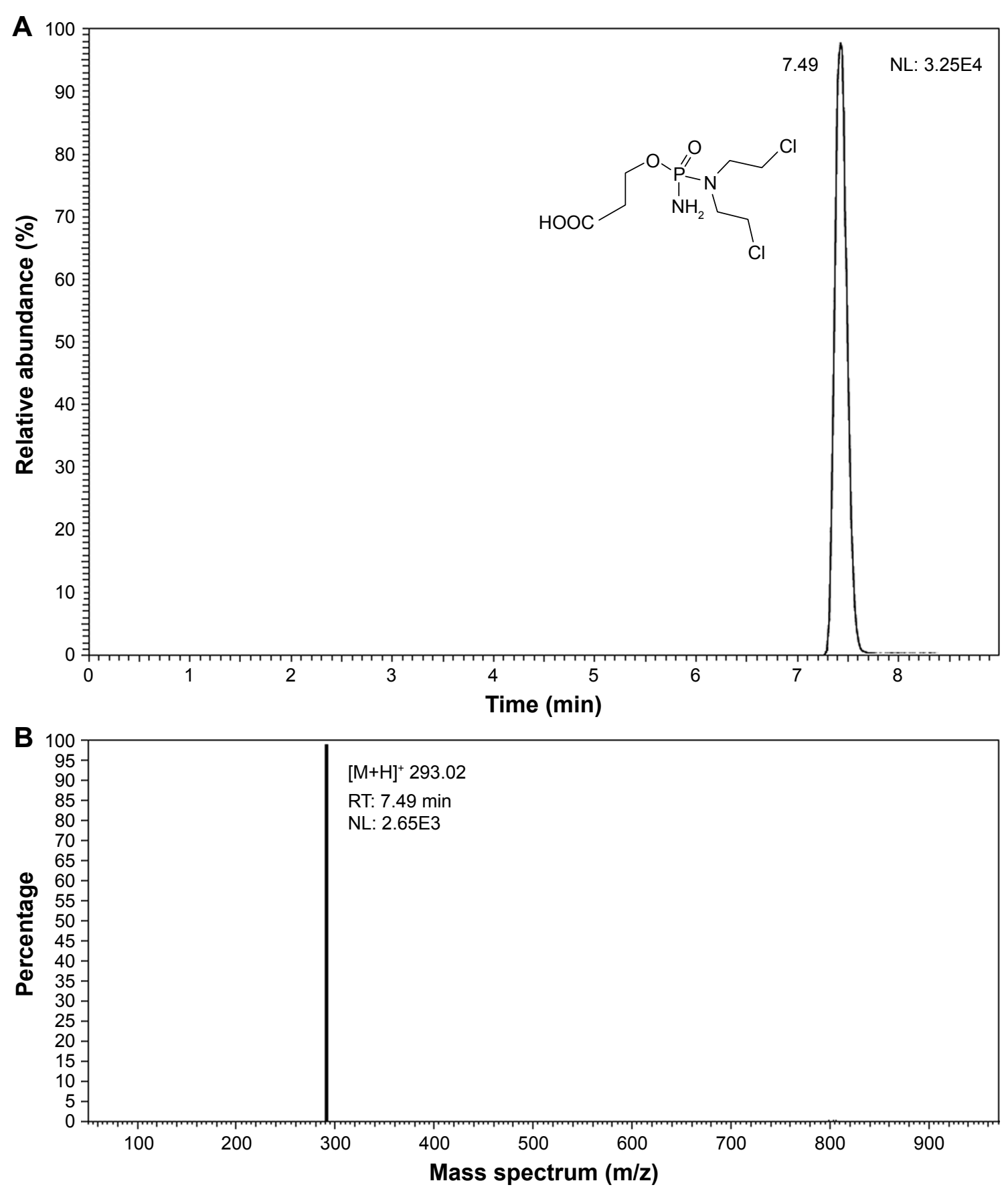

Figure S3 HPLC-MS chromatogram (A) and mass spectra (B) of transformation product 3-((amino(bis(2-chloroethyl)amino)phosphoryl)oxy) propanoic acid from CP in sodium hydroxide $0.01 \mathrm{M}(\mathrm{NaOH})$ solution.

Note: Adduction is represented by $[\mathrm{M}+\mathrm{H}]+$, formed by the interaction of a molecule with a proton (hydron).

Abbreviations: CP, cyclophosphamide; HPLC-MS, high-performance liquid chromatography-mass spectrometry; NL, intensity of the signal; RT, retention time. 

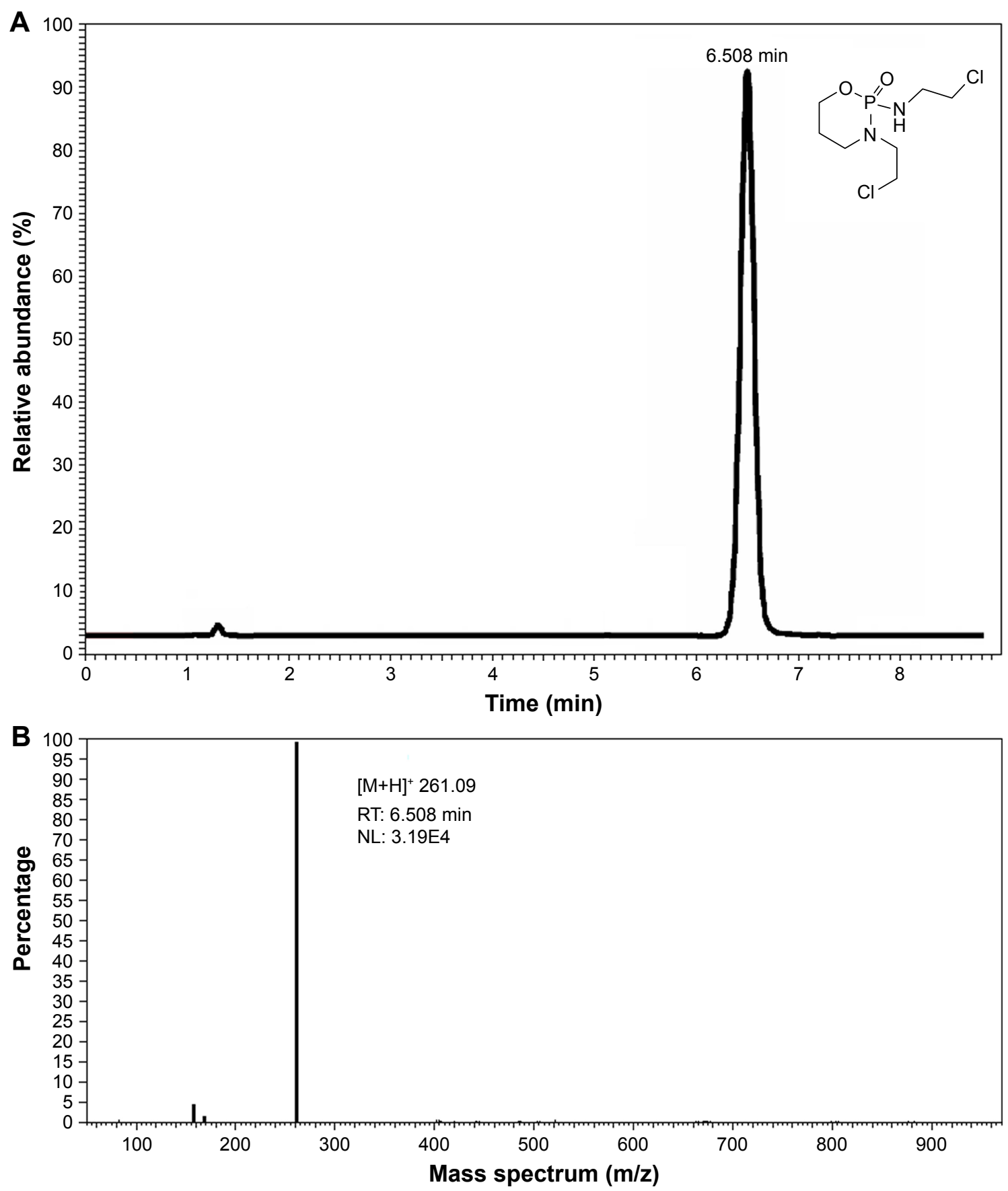

Figure S4 Typical LC-MS chromatogram (A) and mass spectra (B) of IFOS.

Note: Adduction is represented by $[\mathrm{M}+\mathrm{H}]^{+}$, formed by the interaction of a molecule with a proton (hydron).

Abbreviations: IFOS, ifosfamide; LC-MS, liquid chromatography-mass spectrometry; NL, intensity of the signal; RT, retention time. 

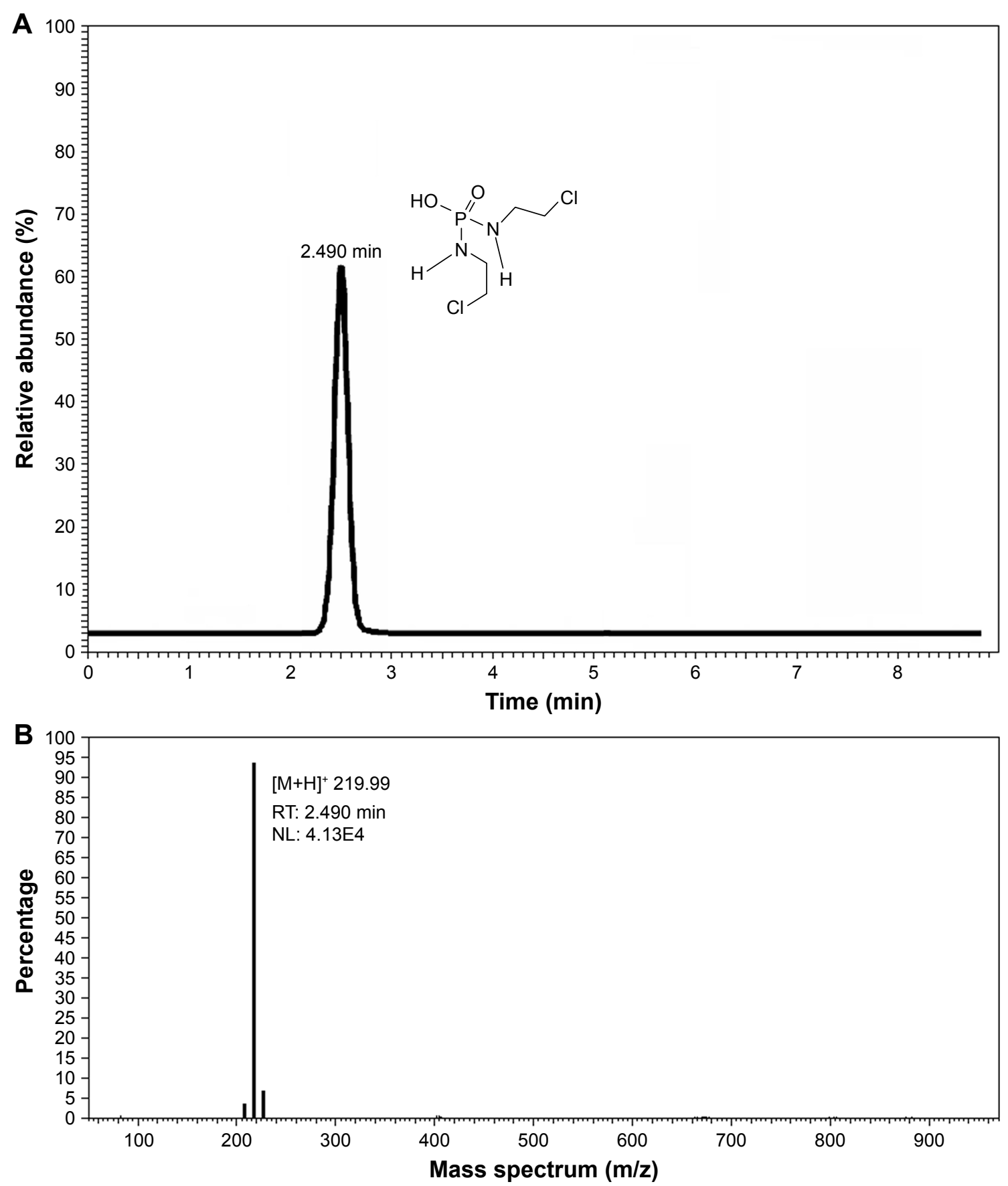

Figure S5 LC-MS chromatogram (A) and mass spectra (B) of the transformation product IFOS-TPI-OH of IFOS in sodium hydroxide $0.01 \mathrm{M}(\mathrm{NaOH})$ solution. Note: Adduction is represented by $[\mathrm{M}+\mathrm{H}]^{+}$, formed by the interaction of a molecule with a proton (hydron).

Abbreviations: IFOS, ifosfamide; IFOS-TPI-OH, 3-((amino(bis(2-chloroethyl)amino)phosphoryl)oxy) propanoic acid; LC-MS, liquid chromatography-mass spectrometry; $\mathrm{NL}$, intensity of the signal; $\mathrm{RT}$, retention time.

International Journal of Nanomedicine

Dovepress

\section{Publish your work in this journal}

The International Journal of Nanomedicine is an international, peerreviewed journal focusing on the application of nanotechnology in diagnostics, therapeutics, and drug delivery systems throughou the biomedical field. This journal is indexed on PubMed Central, MedLine, CAS, SciSearch $\AA$, Current Contents ${ }^{\circledR} /$ Clinical Medicine,
Journal Citation Reports/Science Edition, EMBase, Scopus and the Elsevier Bibliographic databases. The manuscript management system is completely online and includes a very quick and fair peer-review system, which is all easy to use. Visit http://www.dovepress.com/ testimonials.php to read real quotes from published authors. 